\title{
FUNCTION $K$ - AS A LINK BETWEEN FUEL FLOW VELOCITY AND FUEL PRESSURE, DEPENDING ON THE TYPE OF FUEL
}

\author{
UDC 629.3:629.06
}

\author{
Boban Nikolić, Miloš Jovanović, Miloš Milošević, Saša Milanović \\ Faculty of Mechanical Engineering, University of Niš, Serbia
}

\begin{abstract}
Regarding the application of vegetable oil based fuels in diesel engines, it is necessary to fully examine and understand the processes which take place in fuel delivery systems, namely, the processes of injection, mixture formation and combustion as well as emission characteristics. The paper provides an analysis of fuel flow in high pressure tubes of the fuel injection system, with the aim of determining function $K$ as a link between fuel flow velocity and fuel pressure, and observing the influence of certain physical characteristics of the fuel upon the given function. The analysis presents the speed of sound and density, as fuel characteristics which affect the $K$ function. The paper determines the speed of sound, density and bulk modulus for four fuels (pure rapeseed oil RO, biodiesel B100, a mixture of biodiesel and diesel B50, and diesel D), and forms appropriate $K$ functions for each fuel in the pressure range from the atmospheric one to $1600 \mathrm{bar}$.
\end{abstract}

Key Words: Vegetable Oil, Rapeseed Oil, Biodiesel, Speed of Sound, Density, Bulk Modulus

\section{INTRODUCTION}

Vegetable oil based fuels represent a considerable potential as an alternative to the diesel engine fuels. The use of straight vegetable oil as fuel for diesel engines is restricted by a number of factors. Vegetable oils have greater molecular mass than diesel fuel $[1,2]$, often accompanied by inadequate oxidation and thermal stability [1], with higher surface stress, density and viscosity $[1,2,3]$. The research performed using pure rapeseed oil in conventional direct injection diesel engines $[1,4,5]$ has shown that after approximately 50 hours of operation the engine stops working due to the accumulation of coke particles in engine pistons, valves and especially injectors. Simultaneously with the research of the application of straight vegetable oil, studies have also been conducted on the application

Received June 28, 2016 / Accepted October 23, 2016

Corresponding author: Boban Nikolić

Faculty of Mechanical Engineering, University of Niš, Aleksandra Medvedeva 14, 18000 Niš, Serbia

E-mail: nboban@masfak.ni.ac.rs 
of various mixtures of diesel fuels and straight vegetable oil in direct injection (DI) diesel engines $[1,2,4,5,6]$. Forson et al. [6] examine the operation of a single-cylinder, fourstroke DI engine with air cooling, running on various mixtures of diesel fuel and Jatropha oil. The observed exhaust emission is similar to the operation of the diesel-powered engine, regardless of the volumetric composition of mixtures. The best results are obtained when using the mixture with the volumetric composition of $97.4 \%$ diesel and $2.6 \%$ pure Jatropha oil, where a small increase in effective power and degree of efficiency is noted along with a small reduction in specific consumption. However, the study does not contain any information on the operation and state of the engine after a longer period of running on these fuels. The analysis of the composition of exhaust gases from a diesel engine operating on mixtures of diesel fuel and four different vegetable oils (10-20\% of volumetric share) shows a certain rise in the level of NOx, CO and HC emission [7]. Hellier et al. [8] study the operating characteristics of a new generation DI diesel engine with the injection pressure of up to $1600 \mathrm{bar}$, while operating on six different vegetable and algae oils. The oils are heated up to $60^{\circ} \mathrm{C}$ and exhaust gases emission is monitored. The authors have reached the conclusion pointing to a decrease in the level of NOx, but also to an increase in the levels of $\mathrm{CO}, \mathrm{HC}$ and PM in comparison with the engine running on diesel. What is also observed are the differences in the injection timing and the injection duration. The authors emphasize the importance of determining the physical characteristics of vegetable oils for the explanation and prediction of the behavior of injection systems and engine operation as a whole, when using alternative fuels. Reviewing the research into the application of vegetable oil (and different mixtures of vegetable oil and diesel fuel and/or various additives) in diesel engines, it can be concluded that it is necessary either to adjust the engine to the vegetable oil or, vice versa, adjust the vegetable oil to the engine. The diesel engine adjustment to running on vegetable oil has usually brought about an improvement in the engine operation; however, either the results have turned out as not in agreement with the expectations or the requirements and the engine modifications have proved too complicated and costly. Much better results are obtained by adjusting the vegetable oil, especially by changing it chemically with the aim of reducing the molecules by esterification using alcohol. The catalytic decomposition of the vegetable oil structure (the use of waste vegetable oil or the remains of animal fats) using alcohol (most often ethanol or methanol), or the so-called oil esterification, can yield a fuel of far superior characteristics than the basic oils (fats). This fuel is commercially known as biodiesel.

Rapeseed biodiesel has proved to be, in comparison to those obtained from other vegetable oils, one of the most suitable ones from the standpoint of using it as fuel for diesel engines. The majority of other biodiesels possess lower oxidation and thermal stability $[9,10,11]$ with an inappropriate iodine number $[9,10,12]$ or inappropriate cold filter plugging points (CFPP) [9, 13] and compressibility points (CP) [9, 11, 13-17]. Exceptionally, the characteristics of the biodiesel obtained from algae position it high on the list of fuels for diesel engines [9, 18]. However, due to its being a relatively new fuel, with a specific production technology, it is much less produced and used in relation to the biodiesels based on rapeseed oil, soya and oil palms. From the standpoint of the application of biodiesel (and mixtures of biodiesel and diesel fuel) as a fuel in diesel engines, it is necessary to fully examine and understand the processes which take place in the fuel delivery systems as well as the processes of injection, mixture formation and fuel combustion, as well as emission characteristics. Furthermore, it is very important that the characteristics of 
biodiesel are compatible with appropriate standards, and that those characteristics which are not prescribed by any standard (speed of sound, bulk modulus, surface stress, etc.), yet are crucial from the perspective of their influence on the processes of fuel injection, mixture formation, combustion and exhaust gases emission, are examined in detail.

Various researchers have recognized the importance of knowing the speed of sound, density and bulk modulus for the operation of a fuel injection system. Huber et al. [19] determine by measurement the speed of sound and density of examined fuels at the atmospheric pressure, for the temperature range of 278-333 K, and starting from the Molar Helmholtz Free Energy equation, they form a model for calculating fuel characteristics for pressures of up to 500 bar and temperatures of up to $700 \mathrm{~K}$. Tat et al. [20, 21] present the dependence of these characteristics on the pressure of up to 350 bar at 293-313 K. Ott et al. [22] determine the density and speed of sound at 0.83 bar and temperatures of 278 to $338 \mathrm{~K}$. Kegl [23] experimentally determines the speed of sound and density for pressures of up to 400 bar as well as the influence of a temperature change on density (from 273 to $313 \mathrm{~K}$ ). The author also determines the bulk modulus for pressures of up to 400 bar and provides a comparative overview of results obtained by simulation. Dzida et al. [24, 25] measure the speed of sound at temperatures of $293-318 \mathrm{~K}$ and pressures from 1 to $1010 \mathrm{bar}$, the density at the atmospheric pressure, and calculate it at pressures of up to 1010 bar. Payri et al. [26] experimentally determine the speed of sound at pressures from 150 to 1800 bar and temperatures from 298 to $343 \mathrm{~K}$. Two pressure sensors are placed in a $12 \mathrm{~m}$ long "high pressure tube" (with the internal diameter of $2.5 \mathrm{~mm}$ ) at the distance of $8.22 \mathrm{~m}$ from each other. The density is measured at the atmospheric pressure and calculated for higher pressures. Measuring at the atmospheric pressure and temperatures from 293 to $343 \mathrm{~K}$, Freitas et al. [27] determine the speed of sound for different fuels and use the data to calculate and predict the acoustic characteristics of other biodiesel fuels [28]. Daridon et al. [29] present the data for several different fuels where the speed of sound is measured at the atmospheric pressure and the range of temperatures from 283 to $373 \mathrm{~K}$. For the same pressures and with the approach used in [24, 25], Žarska et al. [30] determine the speed of sound for the biodiesel produced from coconut and palm oil. Lopes et al. [31] vary the fuel temperature from 298 to $353 \mathrm{~K}$ at the atmospheric pressure and determine the fuel speed of sound by measurement, with a presentation of data from the literature on the experimental values of the speed of sound for biodiesels of different origin (and some other alternative fuels). Starting from the thermodynamic properties of biodiesel and mixtures, Perdomo et al. [32] model a curve of change in the speed of sound with the change in the fluid temperature, at the atmospheric pressure. Tat and Van Gerpen determine the speed of sound and bulk modulus at pressures of up to 345 bar and temperatures from 293 to $373 \mathrm{~K}$, with the analysis of the change in the values of these quantities for the values of the angle of preinjection and NOx emission [33]. Gautam and Agarwal [34] focus on the influence of fuel temperature (atmospheric pressure) on the characteristics (density, viscosity, speed of sound, bulk modulus, surface stress) of the biodiesel used in India. The determination of the fuel bulk modulus at pressures from 30 to 330 bar and a temperature of $311 \mathrm{~K}$ is the subject matter of the research conducted by Lapuerta et al. [35].

The above research shows that the values of the speed of sound, density and bulk modulus of diesel fuel, biodiesel and their mixtures, increase with an increase in pressure, and decrease with an increase in temperature. Values of the speed of sound, density and bulk modulus increase with the increasing share of biodiesel in mixtures. The complexity 
of the experimental determination of values of the speed of sound and density occurs with an increase in operating pressures above $600 \mathrm{bar}$, regardless of the type of fuel. Here, the major problem is sealing and maintaining the absence of leaks in the apparatus elements during operation at higher pressures in standard methods which work in line with the principle of variable fluid volume.

\section{ANALYSIS OF FUEl Flow IN SMALl DiAMETER TUBES}

Fig. 1 shows a schematic of a mechanically-controlled injection system. The main components of the injection system are a High Pressure Pump (HPP), a High Pressure Tube (HPT) and an injector. The analysis of fuel flow in HPT is based on and draws from $[36,37]$ with certain specificities, and with the aim of identifying and observing the importance and influence of particular physical characteristics of fuel on the operation of the fuel injection system.

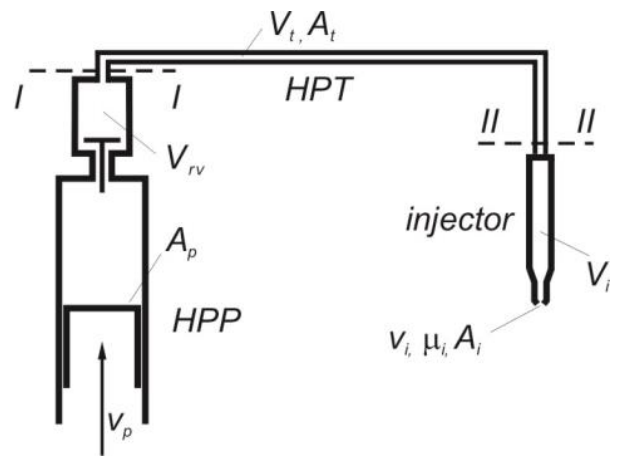

Fig. 1 A schematic of the injection system

$A_{p}, v_{p}-$ HPP piston face area and velocity, $V_{r v}$ - relief valve casing volume, $V_{t}, A_{t}$ - HPT volume and cross-section area, $\mu_{i}$ - active cross-section of the injector, $v_{i}-$ fuel velocity from the injector, $\mathrm{V}_{\mathrm{i}}$ - high-pressure volume part of the injector, $\mathrm{V}_{\mathrm{T}}-$ total volume of the high pressure system $\mathrm{V}_{\mathrm{T}}=\mathrm{V}_{\mathrm{p}}+\mathrm{V}_{\mathrm{t}}+\mathrm{V}_{\mathrm{i}}$

The volumetric fuel flow is, at any moment of time $t$ (or the angle of camshaft $\varphi$ ), defined by piston velocity $v_{k}$ as $A_{p} \cdot v_{p}=\psi(t)$ or $A_{p} \cdot v_{p}=\psi(\varphi)$.

If the process between the pump and the injector would take place without a delay, then there would be no "compression" of the fuel in volume $\mathrm{V}_{\mathrm{T}}$. The link between the initial and the discharge flow (coming out of the injector) would be:

$$
v_{p} \cdot A_{p}=\boldsymbol{\mu}_{i} \cdot A_{i} \cdot v_{i}, \text { that is: } v_{p} \cdot A_{p}=\boldsymbol{\mu}_{i} \cdot A_{i} \cdot \sqrt{\frac{2}{\rho}} \cdot \sqrt{\Delta p}
$$

where $\rho$ is the fuel density and $\Delta \mathrm{p}$ the difference in pressures before and after the injector (nozzle).

In the high pressure part of the installation, fuel has to be treated as a compressible fluid, and the relative change in volume is proportional to the change in pressure: 


$$
\Delta p=-B \cdot \frac{\Delta V}{V}
$$

where $B$ is the entropic bulk modulus of fuel compressibility.

If one takes into consideration fuel compressibility and the total high pressure volume of system $\mathrm{V}_{\mathrm{T}}$, Eq. (1) changes to the form which represents the displaced amount of fuel as a sum of the injected amount of fuel and the remaining amount of fuel in the installation (due to fuel compressibility):

$$
v_{p} \cdot A_{p}=\mu_{i} \cdot A_{i} \cdot \sqrt{\frac{2}{\rho}} \cdot \sqrt{p_{I I}-p_{c y l}}+\frac{d p_{I I}}{d t} \cdot \frac{V_{T}}{E}
$$

where $p_{\text {cyl }}$ is the pressure in the engine displacement and $p_{I I}$ the pressure in front of the injector (Fig. 1, cross-section II-II).

Eq. (3) neglects the influence of inertia and reflection as well as the deformation of the initial flow due to the movement of certain elements (pump, injector) during the injection process. One should bear in mind that the fuel flow velocity is 50 to 60 times smaller than the speed of sound, and that the movement of the displaced amount of fuel is $10-15 \mathrm{~cm}$ for a single cycle. The newly-displaced amount of fuel displaces the fuel already found in the tube in front of it, and the pressure wave travels at the speed of sound.

Not only does the injector react in time with the incoming signal, it also creates the return impulse (characteristic of reflection), so that the characteristic of injection in any moment of time is the consequence of the characteristics of displacement and reflection. The injector nozzle changes the flow cross-section through its movement, thus changing the ratio of the flow cross-section of the injector to the flow cross-section of the high pressure tube, i.e. the condition of reflection.

To analytically solve the problem of fluid flow in small diameter tubes, it is necessary to know the velocity and pressure along the tube at any moment of time. Let us observe a segment of the tube and the control volume in Fig. 2:
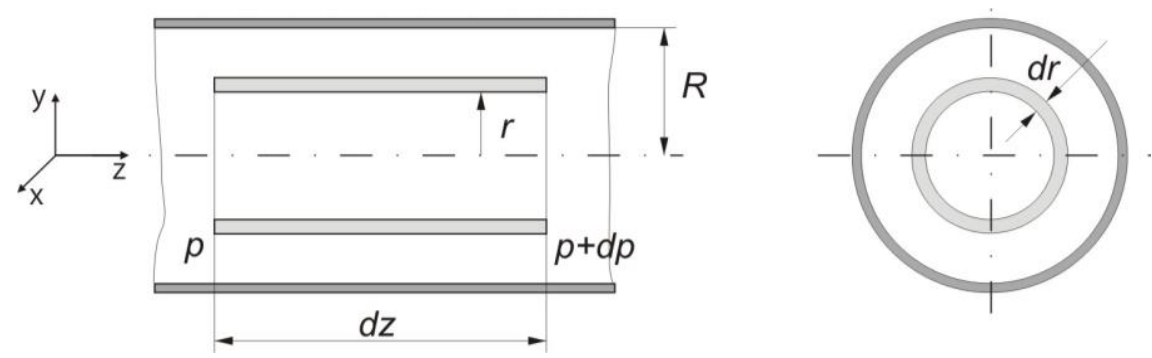

Fig. 2 Control volume

By applying the Navier-Stokes equations of fluid flow to the case in Fig. 2, the following is obtained:

$$
\frac{\partial w}{\partial t}+u \frac{\partial w}{\partial x}+v \frac{\partial w}{\partial y}+w \frac{\partial w}{\partial z}=Z-\frac{1}{\rho} \frac{\partial p}{\partial z}+v\left(\frac{\partial^{2} w}{\partial x^{2}}+\frac{\partial^{2} w}{\partial y^{2}}+\frac{\partial^{2} w}{\partial z^{2}}\right)
$$

where $u, v$ and $w$ are the components of flow velocity in the direction of the $x, y$ and $z$ 
axes, $Z$ is the external forces per unit of fluid mass, $(1 / \rho) \cdot(\partial p / \partial z)$ the pressure force per unit of fluid mass and $v$ the kinematic viscosity.

Taking into account the axisymmetric fluid flow and the fact that the longitudinal dimensions of the tube are much larger than its diameter, the change in pressure in the radial direction is neglected, so that the system can be subjected to a one-dimensional analysis, that is, the constancy of pressure and velocity per cross-section of the tube. If the influence of friction is neglected in the injection process since the tubes are relatively short (around 1 meter), Eq. (4) becomes:

$$
\frac{\partial w}{\partial t}+w \frac{\partial w}{\partial z}=-\frac{1}{\rho} \frac{\partial p}{\partial z}
$$

During the settling process (following injection), the drop in the pressure wave peaks can be described as $p=p_{l} \cdot e^{-k t}$, where $p_{l}$ is the initial value of pressure.

Following the completion of injection, pressure oscillates between the pump and the injector with insufficiently great amplitude to reopen the injector [36, 38]. The settling velocity is directly proportional to the size of the relief volume. On the other hand, too much relief leads to the formation of steam pockets in the high pressure volume which in turn causes the reduction of the system capacity and a delay between the beginning of displacement and the injection itself.

Eq. (5) can further be simplified by neglecting the second member on the left side of the equation (the convective member) due to the uniformity of fluid flow velocity $w$, the fact that the fluid flow velocity is much smaller than the wave propagation velocity, and the constant cross-section of the tube, which yields:

$$
\frac{\partial w}{\partial t}=-\frac{1}{\rho} \frac{\partial p}{\partial z}
$$

The wave travels at the speed of sound, defined as:

$$
a=\sqrt{\frac{B}{\rho}}
$$

The second equation of the link between pressure and velocity is obtained using the continuity equation. Based on the applied one-dimensional analysis of the system, the continuity equation has the following form:

$$
\frac{\partial \boldsymbol{\rho}}{\partial t}+\frac{\partial \boldsymbol{\rho}}{\partial z} w+\frac{\partial w}{\partial z} \boldsymbol{\rho}=0
$$

Using the equation for the adiabatic change in state $p \cdot \rho^{-\kappa}=$ const. and differentiating it according to $t$ and $z$ yields:

$$
\frac{\partial \boldsymbol{\rho}}{\partial t}=\frac{\boldsymbol{\rho}}{p \cdot \boldsymbol{\kappa}} \cdot \frac{\partial p}{\partial t} \text { that is } \frac{\partial \boldsymbol{\rho}}{\partial z}=\frac{\boldsymbol{\rho}}{p \cdot \boldsymbol{\kappa}} \cdot \frac{\partial p}{\partial z}
$$

Substituting Eq. (9) into Eq. (8) yields: 


$$
\frac{\partial p}{\partial t}+\frac{\partial p}{\partial z} w+p \kappa \frac{\partial w}{\partial z}=0
$$

Taking into account the abovementioned, and adopting the fact that flow velocity $w$ is significantly smaller than pressure wave propagation velocity $a$, the convective member of Eq. (10) is neglected and the equation takes on the following form:

$$
\frac{\partial p}{\partial t}+p \kappa \frac{\partial w}{\partial z}=0 \Rightarrow \frac{\partial w}{\partial z}=-\frac{1}{p \kappa} \frac{\partial p}{\partial t}
$$

Eqs. (6) and (11) form a system of partial differential equations:

$$
\frac{\partial w}{\partial t}=-\frac{1}{\rho} \frac{\partial p}{\partial z} \text { and } \frac{\partial w}{\partial z}=-\frac{1}{p \kappa} \frac{\partial p}{\partial t}
$$

whose solution yields the dependence of pressure and velocity on $z$ and $t$, i.e. it enables the knowledge of the values of fluid pressures and velocities in the desired cross-section and moment.

When solving the system of Eqs. (12), one has to take into account the following relations:

- isontropic bulk modulus $B$, which is defined as: $B=\boldsymbol{\rho}(\partial p / \partial \rho)$

- the link between the speed of sound $a$, bulk modulus $B$ and density $\rho: a^{2}=B / \rho$

- the fact that pressure waves propagate at the speed of sound $a$ defined as: $a^{2}=(\partial p / \partial \rho)_{s=c o n s t}$, which when substituted by the adiabatic equation of the change in the state $p \cdot \rho^{-\kappa}=$ const. yields:

$$
a^{2}=\frac{\boldsymbol{\kappa} \cdot p}{\rho}
$$

It is obvious that the analytical solution of the system of Eqs. (12) requires the knowledge of at least two dependencies: $a=a(p, T), \rho=\rho(p, T)$ and $B=B(p, T)$.

Determining the value of the speed of sound, density and bulk modulus in the function of fuel pressure and temperature is important both for the analysis of the process occurring in fuel injection systems and the prediction of the injection system behavior when working with different fuels, particularly those operating at higher injection pressures.

For the sake of a simpler solution of the system of Eqs. (12), one can "conditionally" adopt that $a=$ const., $\rho=$ const. and $B=$ const., keeping in mind that the final form of thus obtained solutions to the system of Eqs. (12) uses the values for $a, \rho$ and $B$ for appropriate working pressures and temperatures.

In that case, the differentiation of the first of Eqs. (12) in the $z$ coordinate, and the second in time $t$ yields:

$$
\frac{\partial^{2} p}{\partial t^{2}}=a^{2} \cdot \frac{\partial^{2} p}{\partial z^{2}}
$$

that is:

$$
\frac{\partial^{2} w}{\partial t^{2}}=a^{2} \cdot \frac{\partial^{2} w}{\partial z^{2}}
$$


Eqs. (14) and (15) are hyperbolic, linear, partial differential equations of the second order. Their solution is usually sought in the Bernoulli form - which is convenient for finding the eigenfrequencies of pressure waves oscillation in the inlet and exhaust tubes of piston engines - or in the d'Alambert form.

For the monitoring of wave propagation, the d'Alambert form of the solution is more convenient [36, 37], and it enables the definition of the current (total) pressure at every place and every moment as:

$$
p=p_{0}+p_{v}+p_{r}=p_{0}+p_{d}
$$

where $p$ is the current pressure, $p_{0}$ the initial pressure in the tubes before the activity of the HP pump, $p_{v}$ the pressure from the pressure waves traveling in the direction of the fuel flow, $p_{r}$ the pressure from the pressure waves traveling opposite to the fuel flow, and $p_{d}$ the dynamic pressure $p_{d}=p_{v}+p_{r}$.

Analogously, the current velocity can be presented as:

$$
w=w_{0}+w_{v}+w_{r}
$$

where $w$ represents the current velocity, $w_{0}$ the initial velocity, $w_{v}$ the velocity which stems from the velocity wave in the direction of the fuel flow and $w_{r}$ the velocity which stems from the velocity wave opposite to the fuel flow.

It is necessary to find the link between the velocity and pressure waves. Observe the tube segment approached by an element of velocity wave $\Delta w_{v}$ (Fig. 3).

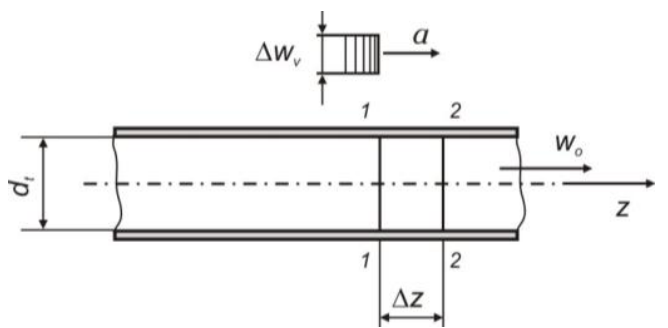

Fig. 3 Elementary volume $A_{t} \cdot \Delta z$ approached by the wave $\Delta w_{v} ; A_{t}=0.25 d_{t}^{2} \pi$

If positive velocity wave $\Delta w_{v}$ moves from the cross-section 1-1 towards $2-2$, the fluid will be compressed in volume $A_{t} \cdot \Delta z$, since the fluid enters 1-1 in interval $\Delta t$ at average velocity $w_{0}+\Delta w_{v}$, and exits it at velocity $w_{0}$.

The time the wave takes to pass through is:

$$
\Delta t=\frac{\Delta z}{a}
$$

and the compressed volume:

$$
\Delta V=A_{t} \cdot \Delta w_{v} \cdot \Delta t
$$

with the elementary volume:

$$
V=A_{t} \cdot \Delta z
$$


The pressure wave travels at a great velocity so that the adiabatic change in the state can be assumed:

$$
\frac{\Delta V}{V}=\frac{1}{\kappa} \cdot \frac{\Delta p}{p}
$$

that is, from Eq. (18) to Eq. (20) one can obtain:

$$
\Delta w_{v}=\frac{a}{\kappa \cdot p} \cdot \Delta p_{v}
$$

where $\Delta p_{v}$ replaces $\Delta p$, as the pressure wave which corresponds to $\Delta w_{v}$.

Eqs. (13) and (22) yield:

$$
w_{v}=\frac{1}{a \cdot \rho} \cdot p_{v}
$$

as an equation which shows the link between fuel flow velocity and fuel pressure. If the function of the link between fuel flow velocity and fuel pressure, $K$, is used to mark:

one obtains:

$$
K=\frac{1}{a \cdot \rho}
$$

$$
w_{v}=K \cdot p_{v}
$$

If the sketch in Fig. 3 is used to observe the wave opposite to the direction of the flow, the following link is obtained:

$$
w_{r}=-\frac{1}{a \cdot \rho} \cdot p_{r}
$$

that is:

$$
w_{r}=-K \cdot p_{r}
$$

due to the opposite direction of the velocity wave causing the attenuation in volume $A_{t} \cdot \Delta z$.

The analysis of the influence of the displacement and reflection characteristics on the injection characteristic using wave propagation $[36,37]$ can present various positions of the wave for fixed observation times.

On the basis of Eqs. (23) and (26), the following can be concluded:

- if the fluid flow direction overlaps with the direction of the velocity wave propagation, the pressure rises; and,

- the velocity and pressure waves have the same sign if they travel in the direction of the fluid flow, and the opposite if they travel in the opposite direction.

The movement of the injector nozzle changes the flow cross-section, thus also changing the reflection condition. During the injection process, $p_{v}$ changes, and when the injector nozzle travels up and down, the ratio of the flow cross-section of the injector to the flow cross-section of the high pressure tube changes as well.

Eqs. (23), (25), (26) and (27) show the link between the velocity and the pressure waves in the direction and opposite to the direction of fuel flow.

Determining the function of $K$ (Eq. 24) necessitates, depending on the type of fluid (fuel), determining $a=a(p, T)$ and $\rho=\rho(p, T)$. 


\section{EXPERIMENTAL SECTION}

The tested fuels are: diesel fuel (hereinafter: D - characteristics in accordance with the EN 590 standard), rapeseed oil (RO - in accordance with DIN EN 51605), rapeseed oil methyl ester - biodiesel (B100 - in accordance with EN 14214), and a mixture of diesel fuel and biodiesel (B50 - volumetric composition: 50\% diesel and 50\% biodiesel).

The method and technique of determining the speed of sound, density and bulk modulus are based on the principle of constant volume and variable mass and density of the fluid in the high pressure part of the installation [38, 39]. The examined fluid (in a vessel with a constant volume - high pressure vessel, HPV) compresses when a controlled fluid mass is pumped. Here the change in pressure is observed, the mass of the pumped fluid is determined and the time of ultrasonic wave propagation (TUWP) through the steel-fuel "sandwich structure" is measured ultrasonically. On the basis of the known path along which the ultrasonic wave travels and the known characteristics of the steel used to manufacture HPV (material, dimensions, time of wave propagation and speed of sound), the time of ultrasonic wave propagation through the working fluid is determined (the time the pressure wave takes to travel the path from the one to the other internal surface of HPV heads, propagating through the working fluid), and the velocity of ultrasonic wave propagation through the working fluid is calculated, depending on the working pressure. On the basis of the known internal volume of HPV (where the vessel dilatation is also taken into consideration $[38,39]$ ) and the calculated fluid mass inside HPV, the density of the fluid is determined depending on the working pressure.

By knowing the speed of sound and density of the tested fuels, the bulk modulus is determined (based on Eq. 7), as well as auxiliary function K (based on Eq. 24).

An ultrasonic probe is positioned on the external surface of the HP vessel heads. An ultrasonic device UD2 - 12 was used in ultrasonic measurements. The impulse echo method with direct contact was applied - special application, with a normal combined ultrasonic probe P111-2.5-K12-002, of 2.5 MHz in working frequency. Corach et al. [40] use probes with working frequencies of $1.53 \mathrm{MHz}, 5.66 \mathrm{MHz}$ and $9.43 \mathrm{MHz}$ for ultrasonic measurements, stating that the results vary only slightly, maximally up to $0.05 \%$.

The schematic of the experimental line for determining the speed of sound, density and bulk modulus of the examined fuels is shown in Fig. 4.

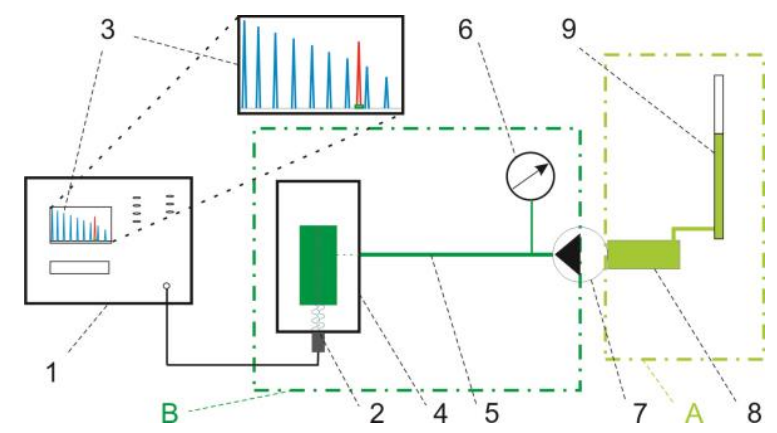

Fig. 4 A schematic of the experimental line

$\mathrm{A}$ - part of the installation at the atmospheric pressure, B - part of the installation at the increased pressure, 1 - ultrasonic defectoscope, 2 - ultrasonic probe, 3 - display, 4 - high pressure vessel, 5 - high pressure tube, 6 - manometer, 7 - high pressure pump, 8 - pump tank, 9 - measuring test tube 


\section{RESULTS AND DISCUSSION}

Measurements were performed for working pressures of up to 1600 bar and fuel temperature of $20^{\circ} \mathrm{C}$. Measurement results are shown in diagrams in Figs. 5 to 9. Values of the time of ultrasonic wave propagation through the working fluid decrease with an increase in pressure for all fuels (Fig. 5). TUWP is the smallest for pure rapeseed oil (RO) and the largest for diesel fuel, at the same pressure. Differences in the values of TUWP for different fuels decrease with an increase in pressure.

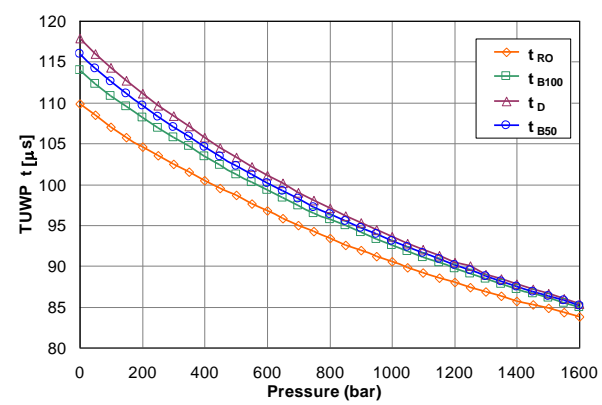

Fig. 5 Time of ultrasonic wave propagation

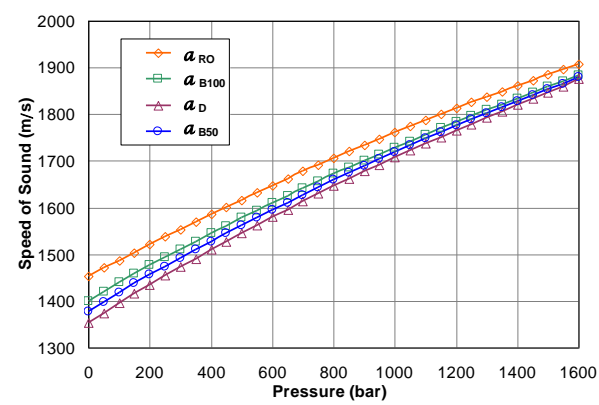

Fig. 6 Speed of sound

Analogously, the values of the speed of sound, for all fuels, increase with an increase in pressure (Fig. 6). Differences in the values of the speed of sound, for different fuels, decrease with an increase in pressure. Moreover, there is a tendency of equalization of the speed of sound values for the fuels B100, B50 and diesel at the pressure of approximately 2000 bar [38]. Density values of the tested fuels increase with an increase in pressure (Fig. 7); however, this increase is smaller in percentage in comparison with the speed of sound values. For the same working pressure, rapeseed oil has the greatest density value while diesel has the lowest. Differences in the values do not change significantly with an increase in pressure. Bulk modulus values of the tested fuels increase with an increase in pressure (Fig. 8). Similar to density, differences in the values of different fuels do not change significantly with an increase in pressure. The largest values of bulk modulus can be found in rapeseed oil and the lowest in

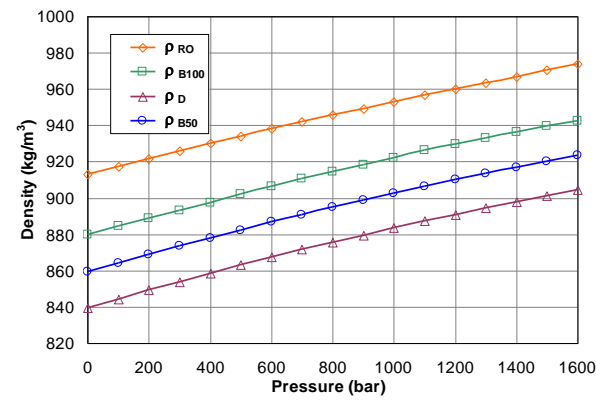

Fig. 7 Density of tested fuels

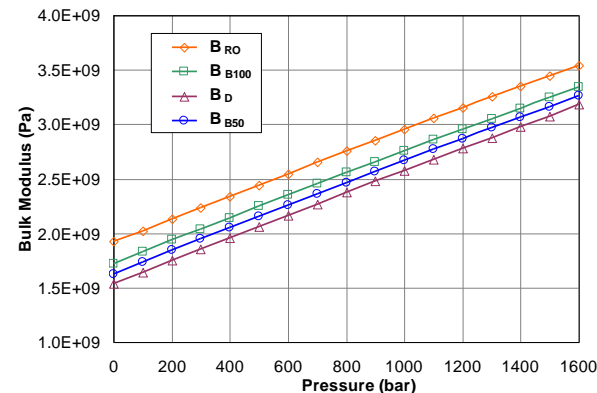

Fig. 8 Bulk modulus 
diesel. Values of the $K$ function decrease with an increase in pressure for all tested fuels (Fig. 9). This tendency is in agreement with the experimental results for the speed of sound and density of the tested fuels (Figs. 6 and 7) and Eq. (24). The largest values of $K$ can be found in diesel while the lowest in rapeseed oil at the same working pressure.

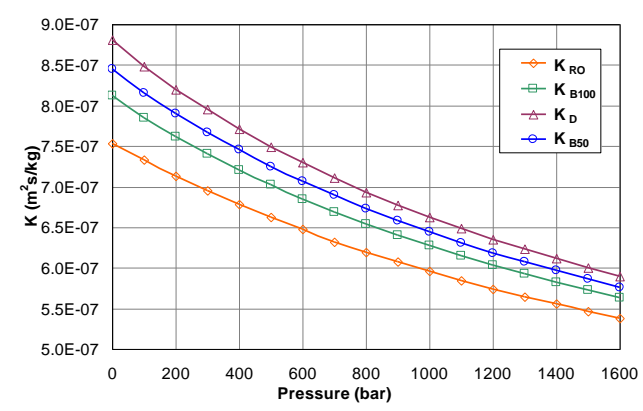

Fig. 9 Function $K$ for tested fuels

\section{CONCLUSION}

Values of the speed of sound, density and bulk modulus increase with an increase in pressure for all fuels. In comparison with the speed of sound at the atmospheric pressure, the speed of sound of the tested fuels at 1600 bar increases for $31.3 \%$ (RO), $34.5 \%$ (B100), 36.5\% (B50) and 38.6\% (D). Furthermore, density increases for $6.7 \%$ (RO), $7 \%$ (B100), 7.4\% (B50) and 7.9\% (D), and bulk modulus for $84 \%$ (RO), 94\% (B100), 100\% (B50) and $107 \%$ (D). Values of the speed of sound, density and bulk modulus, at the same pressures, are different for the tested fuels (Figs. 6, 7 and 8). Since the $K$ function, as a link between fuel flow velocity and fuel pressure, is reversely proportional to fuel speed of sound and density (Eq. 24), the values of the $K$ function are also different depending on the fuel and working pressure. This is particularly important if one knows that, in the mechanically controlled injection systems, the value of the fuel pressure before the injector affects the opening and closing of the injector, and coupled with the fuel flow velocity, fuel characteristics and injection system characteristics, influences the characteristics of the injected fuel spray. In the electronically controlled fuel injection systems, this effect is not significant for the injection timing and duration; yet one has to take into account the influence of the physical characteristics of different fuels on the characteristics of the injected fuel spray, thus also considering the processes of mixture formation, combustion, exhaust gases emission, and effective characteristics of a diesel engine as a whole.

\section{REFERENCES}

1. Stefanović, A., 1999, Diesel engines with fuel based on vegetable oils, (in Serbian), Monograph, Faculty of Mechanical Engineering, Niš.

2. Mehta, A., Joshi, M., Patel, G., Saiyad, M.J., 2012, Performance of Single Cylinder Diesel Engine Using Jatropha Oil with exhaust Heat Recovery System, International Journal of Advanced Engineering Technology, 3(4), pp. 1-7. 
3. Pandey, R.K., Rehman, A., Sarviya, R.M., 2012, Impact of alternative fuel properties on fuel spray behavior and atomization, Renewable and Sustainable Energy Reviews, 16, pp. 1762- 1778.

4. Stefanović, A., Maurer, K., 1992, Some experiences in obtaining rapeseed oil and it's use as an alternative fuel for engines, Engines and motor vehicles '92, JUMV, Kragujevac.

5. Schumacher, L.G., 1996, Engine oil impact literature search and summary, Final Report for the National Biodiesel Board, Columbia, USA.

6. Forson, F.K., Oduro, E.K., Hammond-Donkoh, E., 2004, Performance of jatropha oil blends in a diesel engine, Renewable Energy, 29, pp. 1135-1145.

7. Rakopoulos, D.C., Rakopoulos, C.D., Giakoumis, E.G., Dimaratos, A.M., Founti, M.A., 2011, Comparative environmental behavior of bus engine operating on blends of diesel fuel with four straight vegetable oils of Greek origin: Sunflower, cottonseed, corn and olive, Fuel, 90, pp. 3439-3446.

8. Hellier, P., Ladommatos, N., Yusaf, T., 2015, The influence of straight vegetable oil fatty acid composition on compression ignition combustion and emissions, Fuel, 143, pp. 131-143.

9. http://cdn.intechopen.com/pdfs/23666/InTech-Biodiesel quality standards

10. Xin, J., Imahara, H., Saka, S., 2008, Oxidation stability of biodiesel fuel as prepared by supercritical methanol, Fuel, 87, pp. 1807-1813.

11. Rawat, D.S., Joshi, G., Lamba, B.Z., Tiwari, A.K., Mallick, S., 2014, Impact of additives on storage stability of Karanja (Pongamia Pinnata) biodiesel blends with conventional diesel sold at retail outlets, Fuel, 120, pp. 30-37.

12. Vujicic, Dj., Comic, D., Zarubica, A., Micic, R., Boskovic, G., 2010, Kinetics of biodiesel synthesis from sunflower oil over CaO heterogeneous catalyst, Fuel, 89, pp. 2054-2061.

13. Dunn, R.O., 2011, Improving the Cold Flow Properties of Biodiesel by Fractionation, in Ng T.B. (Ed.), Soybean - Applications and Technology, In.Tech, Rijeka, pp. 211-240.

14. Brunschwig, C., Moussavou, W., Blin, J., 2012, Use of bioethanol for biodiesel production, Progress in Energy and Combustion Science, 38, pp. 283-301.

15. Lahane, S., Subramanian, K.A., 2015, Effect of different percentages of biodiesel-diesel blends on injection, spray, combustion, performance, and emission characteristics of a diesel engine, Fuel, 139, pp. 537-545.

16. Ahmed, S., Hassan, M.Hj., Kalam, Md.A., Rahman, S.M.A., Abedin, Md.J., Shahir, A., 2014, An experimental investigation of biodiesel production, characterization, engine performance, emission and noise of Brassica juncea methyl ester and its blends, Journal of Cleaner Production, 79, pp. 74-81.

17. Varatharajan, K., Cheralathan, M., Velraj, R., 2011, Mitigation of NOx emissions from a jatropha biodiesel fuelled DI diesel engine using antioxidant additives, Fuel, 90, pp. 2721-2725.

18. Islam, M.A., Magnusson, M., Brown, R.J., Ayoko, G.A., Nabi, M.N., Heimann, K., 2013, Microalgal Species Selection for Biodiesel Production Based on Fuel Properties Derived from Fatty Acid Profiles, Energies, 6, pp. 5676-5702.

19. Huber, M. L., Lemmon, E.W., Kazakov, A., Ott, L.S., Bruno, T.J., 2009, Model for the Thermodynamic Properties of a Biodiesel Fuel, Energy \& Fuels, 23(7), pp. 3790-3797.

20. Tat, M. E., Van Gerpen, J.H., Soylu, S., Canakci, M., Monyem, A., Wormley, S., 2000, The Speed of Sound and Isentropic Bulk Modulus of Biodiesel at $21^{\circ} \mathrm{C}$ from Atmospheric Pressure to $35 \mathrm{MPa}$, JAOCS, 77, pp. 285-289.

21. Tat, M. E., Van Gerpen, J. H., 2003, Effect of Temperature and Pressure on the Speed of Sound and Isentropic Bulk Modulus of Mixtures of Biodiesel and Diesel Fuel, JAOCS, 80(11), pp. 1127-1130.

22. Ott, L. S., Huber, M. L., Bruno, T. J., 2008, Density and Speed of Sound Measurements on Five Fatty Acid Methyl Esters at $83 \mathrm{kPa}$ and Temperatures from 278.15 to $338.15 \mathrm{~K}$, Journal of Chemical Engineering Data, 53(10), pp. 2412-2416.

23. Kegl, B., 2006, Numerical Analysis of Injection Characteristics Using Biodiesel Fuel, Fuel, 85(17-18), pp. 2377-2387.

24. Dzida, M., Prusakiewicz, P., 2008, The Effect of Temperature and Pressure on the Physicochemical Properties of Petroleum Diesel Oil and Biodiesel Fuel, Fuel, 87(10-11), pp. 1941-1948.

25. Dzida, M., Jezak, S., Sumara, J., Zarska, M., Góralski, P., 2013, High pressure physicochemical properties of biodiesel components used for spray characteristics in diesel injection systems, Fuel, 111, pp. 165-171.

26. Payri, R., Salvador, F.J., Gimeno, J., Bracho, G., 2011, The Effect of Temperature and Pressure on Thermodynamic Properties of Diesel and Biodiesel Fuels, Fuel, 90, pp. 1172-1180.

27. Freitas, S., Paredes, M., Daridon, J.L. Lima, A., Coutinho, J., 2013, Measurement and prediction of the speed of sound of biodiesel fuels, Fuel, 103, pp. 1018-1022. 
28. Freitas, S., Santos, A., Moita, M.L., Follegatti-Romero, L., Dias, T., Meirelles, A., Daridon, J.L., Lima, A., Coutinho, J., 2013, Measurement and prediction of speeds of sound of fatty acid ethyl esters and ethylic biodiesels, Fuel, 108, pp. 840-845.

29. Daridon, J.L., Coutinho, J., Ndiaye, E.H.I., Paredes, M., 2013, Novel data and a group contribution method for the prediction of the speed of sound and isentropic compressibility of pure fatty acids methyl and ethyl esters, Fuel, 105, pp. 466-470.

30. Žarska, M., Bartoszek, K., Dzida, M., 2014, High pressure physicochemical properties of biodiesel components derived from coconut oil or babassu oil, Fuel, 125, pp. 144-151.

31. Lopes, A., Talavera-Prieto, M.C., Ferreira, A., Santos, J., Santos, M., Portugal, A., 2014, Speed of sound in pure fatty acid methyl esters and biodiesel fuels, Fuel, 116, pp. 242-254.

32. Perdomo, F.A., Gil-Villegas. A., 2011, Predicting thermophysical properties of biodiesel fuel blends using the SAFT-VR approach, Fluid Phase Equilibr. 306, pp. 124-128.

33. Tat, M.E., Van Gerpen, J.H., 2003, Measurement of biodiesel speed of sound and its impact on injection timing, Final Report No. NREL/SR-510-31462, National Renewable Energy Laboratory, U.S. Department of Energy Laboratory.

34. Gautam, A., Agarwal, A.K., 2015, Determination of important biodiesel properties based on fuel temperature correlations for application in a locomotive engine, Fuel, 142, pp. 289-302.

35. Lapuerta, M., Agudelo, J.R., Prorok, M., Boehman, A.L., 2012, Bulk Modulus of Compressibility of Diesel/Biodiesel/HVO Blends, Energy Fuel, 26(2), pp. 1336-1343.

36. Černej, A., Dobovišek Ž., 1980, The fuel supply of diesel and Otto engines, Sarajevo.

37. Urlaub, A., 1989, Verbrennungsmotoren, Band 2, Verfahrenstheorie, Berlin.

38. Nikolić, B., 2016, Research on the injection characteristics of rapeseed and its methyl ester at high pressure in IC engines, (in Serbian) Doctoral Dissertation, Faculty of Mechanical Engineering, Niš.

39. Nikolić, B., Kegl, B., Marković, S., Mitrović, M., 2012, Determining the speed of sound, density and bulk modulus of rapeseed oil, biodiesel and diesel fuel, Thermal Science, 16(2), pp. S505-S514.

40. Corach, J., Sorichetti, P.A., Romano, S.D., 2015, Electrical and ultrasonic properties of vegetable oils and biodiesel, Fuel, 139, pp. 466-471. 